\title{
Investigation of current perspectives for NHS Wales sustainable development through procurement policies
}

\author{
Christos I. Papanagnou, Natalia Shchaveleva \\ Business School, University of Salford
}

\begin{abstract}
Public sector procurement has to operate under the pressure of policies and strict budgets. This paper examines the current perspectives of NHS Wales Shared Services Partnership (NWSSP) on sustainable procurement policies through the environmental, social and economic dimensions. In particular, it investigates the adoption levels of the sustainable procurement policies of buyers (NHS Wales), examines the level of engagement of SMEs to NHS Wales, and explores the support for the existing sustainable procurement function through order-processing analysis of catalogue coverage
\end{abstract}

Keywords: Sustainability, procurement policies;, SME engagement, NHS Wales, catalogue coverage

\section{Introduction}

In the light of environmental degradation, resource depletion, and persistent global poverty, supply mechanisms are increasingly called upon to contribute to the broader organisational goals of sustainable development through the inclusion of social, financial and environmental criteria within the procurement processes, widely known as the Triple Bottom Line (TBL) framework (Srivastava, 2007). Emmett and Crocker (2008) introduced the "5R's" as a procurement function within organisations, securing supplies, materials and services of the right quality, in the right quantity, at the right time, from the right place (source), and at the right cost. However, several management studies have heightened the need for procurement to go beyond this basic objective (Sarkis, Zhu, and Lai, 2011; Erridge and Hennigan, 2012; Walker, 
2015). The role of the procurement function has rapidly changed from one of clerical operation to strategic partnerships, which may be involved in decision-making regarding budget expenditure (Davison and Sebastian, 2011).

It is less than a decade ago that the UK government decided to promote sustainable policies in public sector organisations (Tudor, Marsh, Butler, Van Horn, and Jenkin, 2008). In 2013, the Welsh Government beat tough competition to win a prestigious award for bringing public procurement to the forefront of sustainable transformation. Public sector procurement includes the acquisition of a wide range of goods and services from third parties which support the public services (NWSSP, 2015). In 2013-2014 the expenditure on goods and services (influenceable spend excluding commissioned services) for the NHS Wales was $£ 800$ million while NWSSP processed more than 1000 contracts of approximately total value of $£ 500$ million (Public Policy Institute for Wales, 2016). Public sector procurement policies go through the stages of: identification of need, selection of suppliers, and post-contract award management, which includes disposal. It should be stated that the three main factors that influence public sector procurement are: (i) legislation frameworks, (ii) restricted budget with no possibility for adjustment to meet any additional needs, and (iii) a non-profit orientation of business operation (McCue and Pitzer, 2005).

Despite the UK governments initiatives to attain a high degree of sustainable procurement practices within public organisations, most tend to neglect green procurement considerations when making sustainable procurement decisions at the organisational level (Grose, Bennallick, Nichols, Pahl, and Richardson, 2012). In spite of the fact that public procurement is widely regarded as one of the most effective mechanisms available to governments in advancing public policies (such as the low carbon agenda), public procurers have to operate under the pressure of policies and strict budgets, while simultaneously trying to find the golden ratio between minimum expenditure of taxpayers money and obtaining the best value for money (Correia, Howard, Hawkins, Pye, and Lamming, 2013). Healthcare organisations, such as NHS hospitals, have a high degree of autonomy which can become a hindrance to adopting sustainable procurement policies (Oruezabala and Rico, 2012; Walker and Brammer, 2012). Hospital purchasing administrators, however, consider the adoption of sustainable procurement policies a priority. Their 
argument is that the shift towards more sustainable purchasing operations describes the efforts made by hospitals to include environmental, economic and social dimensions in their arrangements with suppliers (Walker, Di Sisto, and McBain, 2008). In addition, the consequences of the NHSs resistance to change is that in some areas, the ratification of sustainable procurement may be prevented (Cox, Chicksand, and Ireland, 2005). Finally, as a result of various other reasons (e.g., restricted budgets, limitations in suppliers choice, frequent changes at the managerial level), healthcare organisations are somewhat vacillating in their implementation of sustainable procurement policies (Tudor, Baddley, and Mayhew-Manchòn, 2015; Walker and Preuss, 2008).

In terms of social impact, reinvesting in the local economy by supplying locally brings enormous benefits to the community and it is one of the key factors of sustainable procurement. The vast majority of products and services in the UK are provided by Small and Medium-sized Enterprises (SMEs). Even though SMEs constitute the main actors of the country's economy, they encounter numerous difficulties due to the complex nature of the goods and services they produce, as well as in service delivery. For this reason, the NHS is not a large buyer of these products. Although there are still certain categories which are accessible to SMEs, there is a common belief that not being able to meet the capacity is the main obstacle for these types of businesses to become actively involved in the public sector (Munoz, 2009). Moffett and Walker (2015) state that many small to medium-sized businesses have the expertise required to procure to the public sector competently. But even the most dynamic businesses in the marketplace can find it difficult to communicate their star qualities within the constraints of public sector procurement.

One of the most important challenges in the last few years for NHS has been to bring benefits to the community as well as becoming a socially responsible organisation by opening its doors to SMEs and local suppliers. It seems to be more worthwhile, however for most SMEs to contract with local councils, due mainly to the lack of capacity which is manifested by mismatch between the number of staff and amount of time needed to develop a response to tender, an absence in a clear e-procurement framework, and a lack of confidence to bid tenders (Kerley and Wynn, 1991; Salleh, Rohde, and Green, 2006). Loader (2011) has conducted research 
on how local authority procurement practices affect their ability to successfully procure from SMEs. In particular, he carried out a survey amongst 105 local authorities in England in order to investigate how public procurement practices (especially long-term contracts) affect their collaboration with authorities. Almost three-quarters of the respondents (73\%) indicated that developments in procurement were changing the entry barriers for suppliers. SMEs might find it extremely hard to maintain long-lasting contracts with public sector procurement as, normally, these contracts are not flexible and the recent constantly changing conditions, SMEs might suffer unplanned price changes that larger companies could handle. In addition, the tendering process could be very expensive for them.

This study is reinforced by the fact that the UK authorities have made efforts to boost collaboration between government procurement services and local SMEs. Subsequently, a series of initiatives were embarked on to address these problems, including the announcement to have spent $25 \%$ on SMEs by the end of the 2015 Parliamentary year (Cabinet Office, 2015). In the context of government decentralisation, Wales has piloted a study on how to maximise procurement from SMEs within EU legislation and has examined the social clauses within procurement (Thomson and Jackson, 2007). Inspired by this government initiative, NHS Wales is particularly interested in engaging SMEs and Welsh companies with a special interest in minority women-owned businesses (MWOB) (Walker and Brammer, 2012).

NHS Wales is helping towards developing a vibrant Welsh economy that is capable of delivering strong and sustainable economic growth by providing equal opportunities to local producers, at the same time, building stronger communities and reducing social exclusion and poverty (Lindgreen, Swaen, Maon, Walker, and Brammer, 2009). Preuss (2009) studied a county council in the North of England by examining the economic effects of contracting with local suppliers. It was found that local suppliers re-spent a mean of $76 \%$ of contract income within the region, whereas the corresponding average income of non-local suppliers was less than half at $36 \%$ percent. This shows that local company engagement not only creates social advantage but also spawns additional economic benefits for the region as income is reinvested locally.

From a financial point of view, procurement efficacy is often based on quantifying non-cash 
releasing benefits, including cost avoidance and value added practices. In the NHS, these practices are often associated with reviewing and benchmarking contracts - in order to achieve better value for money - and the standardisation of items that is used within health boards (Department of Health, 2016). However, a practice that seems to have no widespread appeal is the catalogue coverage for items ordered by health boards in order to reduce the lead times. Through the reduction of non-catalogue requests, increased catalogue coverage helps healthcare organisations achieve the optimum level of item coverage, resulting in the effective management of the procurement function, as well as in the production of timely and robust management information (Powys Teaching Health Board, 2016).

In the public sector, it is of the utmost importance to ensure that all key categories of expenditure have an appropriate sourcing strategy that the stakeholders agree with (Thai, 2008). This strategy, however, is often subject to the supplier compliance level which is quantified by both contract and catalogue coverage. It goes without saying that an efficient electronic catalogue system maximises coverage and delivers improved compliance. Furthermore, catalogue management can regularly be used for key areas of expenditure. This has been and will remain being the core driver of procurement strategy within public healthcare organisations on account of the fact that delivery reduces risk and maximises savings opportunities. More specifically, well-established catalogue coverage, supported by effective, automated processes, enables the tracking of everything that is purchased, from the point of demand to its use at the agreed pricing, and electronic invoice matching and payment (Department of Health, 2016; Van Raaij, Brandon-Jones, Reunis, and Laming, 2007). Thus, fully electronic systems with extensive catalogue coverage cover pay expenditure and facilitate sustainable procurement. Catalogue coverage is usually expressed in percentages. Take for example the Central Manchester University Hospitals NHS Foundation Trust (CMFT) which has over 95\% of all expenditure on purchase order, while there is a strategy in place for products and services to be included on the catalogue in order to increase coverage to $80 \%$ of the addressable transaction volume by September 2017 (Central Manchester University Hospitals NHS Foundation Trust, 2016). In fact, a well-developed catalogue system with catalogue coverage of $80 \%$ or more of the addressable transaction volumes covers almost all regularly used supplies across the NHS 
organisation (Department of Health, 2016).

The main objective of this paper is to contribute in minimising the gap in knowledge concerning sustainable procurement. The aims of the study are threefold: (i) to investigate the readiness and adoption levels of the sustainable procurement practices of buyers (NHS Wales) across environmental, social, and economic dimensions, (ii) to review the social dimension by examining the level of engagement of suppliers (local SMEs) to NHS Wales, and (iii) to explore the economic dimension through order-processing analysis of catalogue coverage and usage in order to ascertain the level of support for the existing sustainable procurement function. The study examines NHS Wales Shared Services Partnership (NWSSP), which provides a range of high quality, customer focused, professional, technical and administrative functions and services to Local Health Boards (LHBs) and Trusts in Wales. More specifically, two separate surveys were conducted - one with the buyers, the other with SME owners and employees, and finally, an order processing analysis of catalogue coverage and usage was carried out of all-NHS Wales Trusts.

\subsection{NHS Wales Shared Services Partnership}

NWSSP delivers significant savings and benefits, both qualitative and financial to the NHS. The procurement services are comprised of four business divisions: Sourcing (Contracting), Supply Chain (Logistics and Warehousing), Frontline purchasing (Locally based Procurement Teams), and Accounts Payable (Invoice Payment). Each of these divisions aims to provide an end to end procurement service to LHBs and Trusts across Wales, as well as supporting the Welsh Government in the implementation of a number of strategies, including supporting SMEs, sustainability, prudent healthcare and collaboration. Both the Welsh government and NHS Wales have their objectives met through Procurement Services, in general, and Prudent Healthcare in particular, whose principles of service delivery are based on ensuring that quality is at its optimum and interventions are clinically cost effective. The aim of the procurement team is to ensure that the procurement process enhances the quality of outcomes while lowering costs, by working with suppliers to stimulate innovation and improve engagement with the stakeholders.

The sourcing business division comprises of four Category Teams which undertake col- 

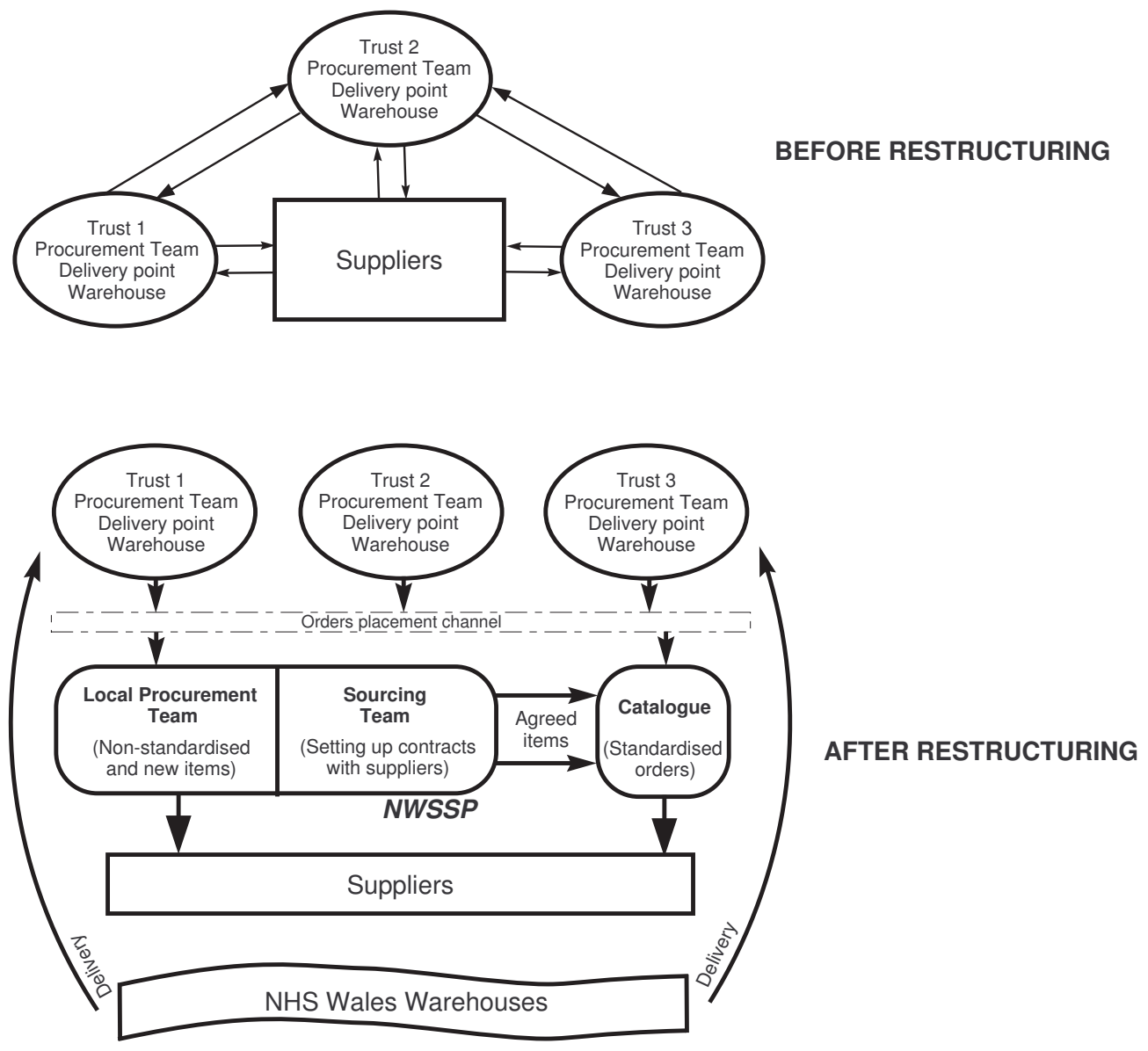

Figure 1: Procurement process in NWSSP before and after restructuring

laborative procurement activity on behalf of the NHS Trusts and Local Health boards across Wales. The teams cover the sourcing work, which ranges from pharmaceuticals, utilities and medical consumables to food. The current procurement policy status can be regarded as transitional. In 2006, the procurement function of each hospital was taken and integrated into a single procurement centre. Shared service partnerships were created in order to make all the administrative functions of all the hospitals in Wales more resilient, effective and collaborative. The restructuring also served purposes for the standardisation of items ordered from various Health Boards and Trusts, as well as to encourage different hospitals to use the same items, which in turn helps to attain much bigger orders that lead to significant price reductions. Last but not least, the ability to monitor the needs and demand for the sum of hospitals rather than each one separately, reduces the risk of making unnecessary purchases, thus saving on their associated costs. Figure 1 shows the procurement process before and after restructuring.

A newly established sourcing team is now in the process of renewing and renegotiating 
the set of contracts and making them applicable to all NHS Wales Trusts. The purpose is not just about reducing costs but also providing better quality products and services. In addition, the consolidation of the warehouses will provide better stock control. One further advantage of centralised procurement for NHS Wales according to the four-part plan is the achievement of economies of scale through centralised procurement and greater aggregation (NHS Supply Chain, 2013). This will provide the ability to craft the common aims, mission and strategies for future development, which includes the implementation of sustainability policies of procurement processes. Note that centralised procurement may lead to glitches due to the physical distance between the local procurer and the central unit (Hayes, 2010). NHS faces great challenges in terms of time response, coordination and communication. However, due to the relatively small size of Wales, these issues can be easily alleviated by ensuring that local markets remain competitive and no monopolies emerge (Cresswell and Sheikh, 2015).

\subsection{Sustainability policies within NWSSP}

Sustainability in the NWSSP is subject to European Union (EU) public procurement directives and norms (European Commision, 2003). The following sustainability policies are currently implemented within NWSSP: (i) Packaging policy, (ii) Transport policy, (iii) NWSSP procurement policy, (iv) NWSSP supplier policy, and (v) Corporate social responsibility policy.

There are also twelve sustainability key objectives, where sustainable procurement policies are instigated (NWSSP, 2015). (i) Ensure procurement activities are conducted in an ethical manner and according to the UK Government Health Strategy and The Ethical Procurement for Health. These constitute guidance and toolkits, providing a flexible framework through which the organisation can benchmark its performance. (ii) Promote equality and diversity in its activities. This is quite important in order to identify NHS Wales level of diversity and engagement with SMEs and local suppliers within procurement functions. (iii) Support the "Securing the Future" document, which is an exercise in assessing NHS Wales contribution to the UK goal of being among EU leaders in sustainable procurement. (iv) Better engagement with stakeholders which examines whether appropriate processes are in place in order to implement more innovative approaches to sustainability. This includes the assessment of the suppliers compliance level. (v) Working with the third sector organisations. NWSSP can commission some 
services - based on identified shortages in catalogue coverage - to third sector private organisations (e.g., Red Cross, British Trust for Conservation Volunteers (BTCV) etc.) by promoting innovation and quality. (vi) Develop organisational values and integrate CSR principles into practice. This is to ensure that suppliers are not engaged in any activity, which would constitute a bribery offence, as well as being expected to ensure their employees and sub-contractors act in line with the Human Rights Act 1988. (vii) Measure performance on sustainability, which includes the adoption of metrics to benchmark environmental performance, examine the social impact, and assess the financial measures related to procurement processes. (viii) Implement the Opening Doors Charter which ensures that SMEs have the opportunity to compete equally. The NWSSP recognises the contribution of SMEs, thus, the Welsh Government has launched a programme of initiatives to support SMEs in bidding for public sector procurement opportunities. This can be better supported by aligning demand with catalogue and contract coverage. (ix) Reduce contribution to climate change by saving energy and minimising the impact of the fleet. NWSSP is aiming to introduce energy efficiency initiatives and working with suppliers to reduce carbon print in the manufacture and on-going performance of goods and services. (x) Reduce, reuse and recycle packaging. This specific objective is to reuse at least $25 \%$ of total tonnage in line with government aims, ensuring the right waste disposal, working with suppliers towards using recycling packaging and carrying out periodic audits and site visits of fleet maintenance contractors. (xi) Minimise waste. Waste minimisation is one of the key strategic sustainability goals which is in line with the Welsh governmental strategy to recycle $70 \%$ of waste by 2050 . Thus, NWSSP Procurement Services are committed to reducing the amount of material disposed (xii) Minimise the negative impact of transport used by both NHS Wales and its suppliers. This objective can be met by establishing a low carbon transport network, which promotes access rather than mobility. NWSSP must ensure that hauliers transport vehicles have Euro $\mathrm{V}$ engines or better and always encourage the use of alternative fuels (5\% additive). Table 1 shows the relevance of these twelve objectives with the three study aims: readiness level of NWSSP personnel, engagement level of SMEs, and order processing through catalogue coverage. 
Table 1: Sustainability key policies and their relevance

\begin{tabular}{ll}
\hline Sustainability key objectives & Relevance \\
\hline Ensure procurement activities are conducted in an ethical manner & SPP \\
Promote equality and diversity in its activities & SMEE, SPP \\
Support the "Securing the Future" document & SPP \\
Better engagement with stakeholders & CCU, SPP \\
Working with the third sector organisations & CCU, SSP \\
Develop organisational values and integrate CSR principles into practice & SSP \\
Measure performance on sustainability & SSP, CCU \\
Implement the Opening Doors charter & SMEE, CCU \\
Reduce contribution to climate change & SSP, CCU \\
Reduce, reuse and recycle packaging & CCU, SSP \\
Minimise waste & SSP \\
Minimise the negative impact of transport used & SSP \\
\hline *SPP. Sustainable procurement practices, &
\end{tabular}

\section{Methodology}

The sample for the first survey consisted of thirty-eight (38) employees who completed a questionnaire at work during work hours, which is why there was a $100 \%$ response to the survey. The respondents were placed into three groups: 14 were in the non-clinical group who were people in procurement and management and made up (36.8\%) of the overall sample, 16 (42.1\%) were in the clinical group (nursing staff), and 8 (21.1\%) were in the medical group (doctors). The questionnaire consisted of seven items, which respondents had to rate on a 5point Likert scale where $1=$ strongly disagree and $5=$ strongly agree. The seven statements, that were selected for the questionnaire and which best apply to NHS Wales according to the official procurement services sustainable procurement policy (NWSSP, 2015), and that have also been explored in the past by other authors are: 1) Use of life-cycle analysis for recycling/re-use, 2) Considering suppliers locations in a safe manner, 3) Asking suppliers to commit to waste reductions, 4) Purchasing from MWOB, all adopted by (Carter and Jennings, 2004), 5) Purchasing from small suppliers, 6) Purchasing from local suppliers both replicated from (Walker and Brammer, 2012), and 7) Working with third sector organisations (Feeley and O'Mally, 2015). The first survey investigates the study question: How do procurers within NWSSP evaluate the level of implementation of sustainable practices according to the Triple Bottom Line?

This question was prompted by the fact that NWSSP use two main tools to drive and improve sustainable procurement performance. (i) the Sustainable Procurement Assessment Framework (SPAF), and (ii) the Sustainable Risk Assessment Template (SRA). Recently NWSSP has introduced the new updated template where products need to be certified as ethically sourced, such as those certified by a member of Fairtrade Labelling Organizations International or equivalent (Bloomfield, 2015). Given the complexity of procurement function in NHS 
Wales, this question seeks answers to what extent the management system and procurers integrate key environmental, social and economic aspects and, thus, it captures the support and adoption level of procurers for sustainable practices. Note that the inclusion of both the clinical and non-clinical group (who are involved in procurement and management) helps to apprehend the level of implementation of sustainable practices across all NHS personnel engaged with procurement functions.

The second survey was conducted on participants who are employed in SMEs contracted to NWSSP, and they are registered on a supplier list. The aim of this survey was to investigate what the barriers and obstacles for SMEs are to selling goods and services to NHS Wales. The following four obstacles were chosen as items following discussions in the format of informal interviews with SME representatives: Time, Complexity, Experience and Capacity. The sample for the second survey comprised 162 respondents from 94 SMEs involved in the following sectors: Construction (16\%), Transportation (11\%), Catering (11\%), Medical (10\%), IT (10\%), Consulting (9\%) while $7 \%$ were active in a variety of areas, such as agricultural, low-skill manufacturers, and reprographics, finally $26 \%$ were "new starters". Respondents completed a three-item questionnaire (first ranking; the other two dichotomous answer with yes/no). The second survey investigates the study question: How strong is NHS Wales engagement with SMEs and local suppliers, in terms of engagement in procurement processes? This question was prompted by the fact that in the UK, since 2013, SMEs accounted for $99.9 \%$ of the 4.9 million private sector businesses and $48.1 \%$ of private sector turnover (Shaw, 2011). This extremely high percentage shows that SMEs are one of the main players of the nation's economy. However, it appears that the more trade in products and services, the more difficulties SMEs encounter in business operation (Reijonen, Tammi, and Saastamoinen, 2014).

Finally, data on 53,000 all-Wales Trust orders processed to sellers for the period of January - March 2015 were collected and analysed. The two types of orders analysed were: (a) orders for standardised items that belong to the catalogue (the items included in NWSSP database, which are forwarded to relevant suppliers), and (b) orders for non-standardised items, which are placed by buyers and are processed manually. The study question examined was: How NWSSP order-processing is facilitated by catalogue coverage? This question was prompted by 
the fact NWSSP and NHS Wales aim to provide world-class service to their patients and also because procurement process in NWSSP is transitional and it has just recently gone through restructuring. Prompt services to patients could be classed as a component of the sustainability of healthcare organisations, since disrupted operations affect the community (Customer Board Members, 2012). However, contract and catalogue coverage of items is one of the biggest concerns within NWSSP (Hywel Dda University Health Board, 2016; Powys Teaching Health Board, 2016).

\section{Findings and Discussion}

\subsection{The level of awareness of sustainable policies within NWSSP}

According to Preuss (2009), it is only recently that sustainable public procurement policies have been studied. Sustainability is a very high-priority issue not just for NHS Wales but for many health organisations (Elkington, 2002). Table 2 presents the findings of the first survey which examined the level of awareness that public procurers had regarding sustainable procurement. The findings show that all three groups of respondents. i.e., non-clinical, clinical, and medical, had a similar level of awareness in sustainable practices. As can be seen from the Table 2, the highest mean was asking suppliers to commit to waste reduction with 3.25 , while uses of life-cycle analysis for recycling/re-use was at 2.90. More specifically, the clinical group had the highest percentage at 3.75, while the other two groups had 3 each. These two items are both related to the environmental dimension.

As regards the social dimension, all three groups of public procurers in the NHS Wales seem to have the least awareness for purchasing from Minority Women Owned Businesses (MWOB) (mean 1.00), while the statements about purchases from small suppliers and local suppliers have also received the lowest scores, 2.15 and 2.10, respectively. More specifically, for small suppliers, the medical group was the highest at 2.75 , followed by the non-clinical group at 2.1 and the clinical group at 1.6. In contrast, the non-clinical group had the highest score (2.3) for local suppliers with the other two groups both at 2. Thus, our findings indicate that employees within NWSSP consider the environmental dimension as the strongest and the social dimension across TBL as the weakest, an outcome that is in line with Lindgreen et al. (2009) 
who found that most of the laws and regulations associated with environmental sustainability are mandatory, whereas most of the policies implemented towards social sustainability are voluntary or optional.

Concerning the economic dimension, suppliers location in a safe manner with a mean of 2.78 , it can be seen that the non-clinical group gave it the highest score (3.6), with the medical and clinical groups giving 2.5 and 2.25, respectively. Finally, the mean score for works with third sector which relates to charities is the second highest at 2.93. In terms of the individual groups, it follows the same pattern as above with the non-clinical giving the highest score followed by the medical and clinical at 3.4, 3, and 2.4, respectively. Both these findings indicate that while the non-clinical group considers the economic factor to have the highest importance, the clinical group regarded it to have the least importance. It should be noted here that although works with third sector could also be included in the social dimension, we chose to include it in the economic one as it produces savings for the procurers (Feeley and O'Mally, 2015).

Another section of the questionnaire included the situational question: "if you had to make a decision between a supplier who offers cheaper products whilst having standard environmental certificates or a supplier offering a more expensive product but having additional environmental certificates and who implemented more approved ethical standards in the company, which one would you choose?". The finding for this were that 28 out of the 38 respondents (74\%) stated that they would choose the first supplier, which suggests that the majority of buyers would most likely put best price of products or services before additional sustainability assets. Another question concerned the attendance of training courses on sustainability. The findings showed that $81.6 \%$ of the procurers have never attended any training on sustainable procurement.

Table 2: Level of awareness of public procurers

\begin{tabular}{lccccc}
\hline Statement & Non-clinical group & Clinical group & Medical group & Standard deviation & Average score \\
\hline Number of respondents (percentage) & $14(36.8 \%)$ & $16(42.1 \%)$ & $8(21.1 \%)$ & & \\
Uses life-cycle analysis for recycling/re-use & 2.7 & 3.25 & 2.75 & 0.30 & 2.90 \\
Supplier's locations in a safe manner & 3.6 & 2.25 & 2.5 & 0.72 & 2.78 \\
Works with third sector organisations & 3.4 & 2.4 & 3 & 0.50 & 2.93 \\
Ask suppliers to commit to waste reductions & 3 & 3.75 & 3 & 0.43 & 3.25 \\
Purchases from small suppliers & 2.1 & 1.6 & 2.75 & 0.58 & 2.15 \\
Purchases from local suppliers & 2.3 & 2 & 2 & 0.17 & 2.10 \\
Purchases from MWOB & 1 & 1 & 1 & 0.00 & 1.00 \\
\hline (1 = strongly disagree) and (5 = strongly agree) & & & & &
\end{tabular}




\subsection{The level of SME engagement in sustainable procurement}

Table 3 presents the results of the second survey, which was anonymous, and which examined the level of SME engagement in sustainable procurement. It should be noted that $26 \%$ of the SMEs were fresh starters who foster green thinking and are more cooperative with sustainable procurement policies. In view of the fact that these SMEs had little business experience at the time the survey was conducted, they wish to explore further procurement opportunities by contracting to the public sector.

Firstly, the employees of the SMEs were asked to indicate by ranking the order of what they considered to be the most serious obstacles in adopting sustainable procurement practices. The biggest obstacle appears to be the Time factor with a mean of $44.40 \%$. This was followed by Capacity (mean 25.08\%), Complexity (mean 20.84\%) and last was Experience (mean 9.68\%). Thus, there is an indication that procurement practices within NWSSP significantly affect the ability to successfully procure from SMEs due to time constraints especially for SMEs trading in construction (55.40\%) and medical $(51.10 \%)$ sectors. This is in agreement with Hong and Kwon (2012) who found that public procurement policies, especially for long-term contracts, negatively affect the collaboration between SMEs and public organisations. Possible reasons could be the lack of flexibility, unforeseen price changes, and the high costs involved in becoming part of the tendering process in the British Health sector. The survey revealed also capacity as the second most prevailing obstacle, and, in particular, SMEs offering catering services demonstrated this as the most dominant obstacle (35.60\%) followed by consulting companies $(26.00 \%)$. Although many businesses have the expertise to compete, even the most dynamic ones may find it difficult to completely satisfy the requirements of sustainable procurement in the public sector in order to provide top quality products and services (Loader, 2011; Grose and Richardson, 2013). Regarding business starters, they find lack of experience (40.10\%) as the most prevailing obstacle in joining NHS Wales procurement practices, which was also observed by (Flynn and Davis, 2015). In fact, the lack of engagement of SMEs in providing procurement services due to the four obstacles compromises the sustainability of procurement practices within the public sector.

The second item of this survey explored the level of SME awareness in supplying to NHS 
Wales. The high level of awareness in supplying (62\%) tends to support the fact that UK health organisations have put effort into boosting collaboration between government procurement services and local SMEs. Inspired by this government initiative, NHS Wales is interested in SME engagement, while NWSSP in particular expressed an interest in collecting primary data from SMEs about their level of understanding regarding opportunities to supply to Welsh hospitals. Lastly, the third item of the survey examined the level of joint-forces for binding purposes, which the findings show is significantly low (23.02\%). This outcome could be mainly due to bidding schemes that might not suit the nature of many SMEs, while the lack of trust is a hindrance to dividing both responsibilities and profits amongst the different companies. Furthermore, joint bidding is a relatively new opportunity for SMEs to participate in public contracts. Establishing joint ventures and building consortia could, in the future, be the main way for SMEs to participate in tenders, and is currently being highly promoted by NHS Wales. In April 2013, a consortium consisting of eight SMEs won a bid to provide mental health services called Parabl Talking Therapies Partnership (Parabl, 2016).

Table 3: Level of SME engagement with NHS

\begin{tabular}{llcccccccc}
\hline Sector & Percentage & \multicolumn{2}{c}{ Obstacles towards sustainable procurement (\%) } & \multicolumn{2}{c}{ Awareness of supplying (\%) } & \multicolumn{3}{c}{ Joint binders (\%) } \\
& & Time & Complexity & Capacity & Experience & Yes & No & Yes & No \\
\hline Business starters & $26 \%$ & 20.70 & 16.80 & 22.40 & 40.10 & 60.60 & 39.40 & 25.10 & 74.90 \\
Construction & $16 \%$ & 55.40 & 26.30 & 16.70 & 1.60 & 71.20 & 28.80 & 13.30 & 86.70 \\
Transportation & $11 \%$ & 46.80 & 27.30 & 24.70 & 1.20 & 55.90 & 44.10 & 23.30 & 76.70 \\
Catering & $11 \%$ & 47.10 & 15.30 & 35.60 & 2.00 & 60.10 & 39.90 & 27.80 & 72.20 \\
Medical & $10 \%$ & 51.10 & 16.90 & 24.70 & 7.30 & 59.2 & 40.8 & 18.8 & 81.2 \\
IT & $10 \%$ & 48.80 & 20.30 & 25.60 & 5.30 & 60.30 & 39.70 & 25.30 & 74.70 \\
Consulting & $9 \%$ & 40.10 & 24.20 & 26.00 & 9.70 & 66.70 & 33.30 & 24.40 & 75.60 \\
Other & $7 \%$ & 45.20 & 19.60 & 24.90 & 10.30 & 62.00 & 38.00 & 26.20 & 73.80 \\
\hline & Averages: & 44.40 & 20.84 & 25.08 & 9.68 & 62.00 & 38.00 & 23.02 & 76.98 \\
\hline
\end{tabular}

The study findings suggest that it is difficult for SMEs to take part in public healthcare tenders because in most cases it is not in their best interest to place an offer. In addition to this, it is difficult to maintain long-lasting contracts with public sector procurement. In fact, there are only two predominant categories for bidding: commissioning and food. Commissioning is mainly oriented in procuring mental health and house-care services, which are mostly provided by third sector organisations that partially fulfil NWSSP plans in the implementation of corporate social responsibility policies. Food attracts many Welsh companies due to the fact that Wales has a vibrant agricultural industry. Additionally, the Welsh government supports the Welsh procurement initiative by encouraging public organisations to be supplied locally (NWSSP, 2015). 
In 2003, the Welsh Procurement Initiative launched an SME Development Pathfinder project to primarily form a Food Group of catering and procurement managers in the public sector, whose aim was to identify local SMEs to become active in the food industry for "in-house collaboration on food procurement including hospitals. Although the project demonstrated that food quality was considerably improved when supplied locally, there were hurdles that needed to be overcome. For a long time, the NHSs main focus was to reduce costs, which resulted in lower budgets for ingredients, fewer highly skilled professionals, as well as less catering equipment and a weaker catering infrastructure. This caused fragmentation in demand, where smaller amounts had to be delivered to over 5,000 outlets within short delivery windows (Tudor et al., 2015).

\subsection{Catalogue coverage and order processing}

A significant reason for analysing the relationship between order-processing and catalogue coverage was to examine the effects of the NWSSP procurement process restructuring. In our study, the number of all-Wales Trust orders processed to the external sellers, e.g., local SMEs, for the period of January - March 2015 was analysed. The findings showed that from an overall 53,000 items, 9,143 were orders that should have been placed through a catalogue (and perhaps even more up-to-date through an e-catalogue). In addition, considerable lead-times resulted from serious delays and unnecessary steps in order-processing. The lack of essential information supplied in catalogues about a product or service, along with the barriers in order-processing and distribution were found to contribute negatively to the sustainability of the procurement function, which is in line with (Harvie, Mikkelsen, and Shak, 2009; Hayes, 2010). An example of this is that throughout the data collection and analysis of orders, we saw that there was a consistent delay in the delivery of medical gas which could have critical consequences. Better order-processing provides transparency throughout storage and distribution services across NHS Wales, which operate from three regional stores based in Bridgend, Denbigh and Cwmbran, together with some smaller satellite/receipt and distribution stores (NWSSP, 2015). Thus, catalogue coverage can provide better control of cargo vehicle routing, as well as excessive stocks, which often results from insufficient utilization of catalogue coverage.

The examination of catalogue coverage involved sending notification letters to end users, 
whose orders had been incorrectly placed revealing two main factors contributing to this: (1) Lack of training - there are multiple ways to place an order through a catalogue. Twelve of the participants stated that they were not aware of the procedures in response to the question regarding the different ways of using the Oracle based catalogue. (2) Lack of personnel placing orders - very often hospitals suffer from staff shortages with no administrative assistant available to process the orders, making the whole process slow and much less efficient. This finding is in agreement with the study by Hinrichs, Jahagirdar, Miani, Guerin, and Nolte (2014), who highlight the importance of better utilisation of catalogue cover-age in District Health Boards in New Zealand by providing training opportunities to personnel and generating savings through consistent order-processing and systems. Thus, continuous improvement of catalogue coverage could provide several benefits: (i) substantial decrease in lead times, (ii) save work time for the buyers freeing them to concentrate on more important tasks, and (iii) improvement in service quality.

\section{Discussion and Conclusion}

The current perspectives of NHS Wales sustainable procurement policies were examined through environmental, social and economic dimensions. This research showed that NHS employees perceived sustainability as an important factor affecting procurement policies. In addition, with regards to the environmental impact, the study results also showed that suppliers' (SMEs) commitment to waste reduction, safe movement of products to facilities, life-cycle analysis to evaluate environmental friendliness of products for recycling and re-use, received considerable consideration. A clear indication was given that the decision-making process regarding public procurement in healthcare has shifted from opting for the cheapest bid of a product to selecting the most economically advantageous contract (best value for money).

Procurers seem to regard the social dimension as the least important, giving the lowest scores to covering engagement with SMEs and MWOBs. It is thus proposed that the NWSSP should take further initiatives to enhance engagement with small, local or minority owned businesses, as our findings indicate that by buying locally, healthcare organisations can greatly benefit the community as reinvesting in the local economy is one of the key factors to sus- 
tainable development. It appears that the major obstacles to SMEs active engagement in the public sector are the time and capacity factors. Another important finding in this study was the fact that a substantial number of small to medium companies are unaware of the opportunity to supply to the NHS, which could successfully be rectified by the NWSSP reaching out and raising SMEs awareness of the issue.

Public procurers need to investigate the most efficient linkage between catalogue coverage and sustainable procurement. It was found that better catalogue coverage management provides more prompt services for the end users, which in turn impacts on sustainable procurement and the overall hospital performance. In terms of sustainable procurement, current and prospective suppliers should be given clear guidance on how to procure for contracts, while the procurement team should aim to accept orders from health boards for standardised items or even for items that have never been ordered before. Also, the catalogue should be well maintained by ensuring that pricing is up to date (Preuss, 2009).

This research suggests that in terms of environmental sustainability, procurement policies can be enhanced by placing emphasis on long-term sustainability. This will help NWSSP to measure the impact of sustainable procurement on NHS Wales and society. Furthermore, although the NWSSP is very interested in working with local companies, it seems to be extremely hard to find Welsh SMEs trading in certain sectors that are able to form joint-binders (Walker and Preuss, 2008). The socially responsible dimension could be improved by creating open days for suppliers and SMEs. To conclude, the study limitations are due to the small sample size concerning only NHS Wales. It is proposed that further research be conducted in sustainable public procurement, and catalogue coverage and usage, on a wider scale, perhaps encompassing all NHS Trusts in the United Kingdom.

\section{References}

\section{References}

Bloomfield, C., 2015. Putting sustainable development into practice: hospital food procurement in Wales. Regional Studies, Regional Science 2 (1), 552-558. 
Cabinet Office, 2015. Social Value Act Review (www.gov.uk).

Carter, C. R., Jennings, M. M., 2004. The role of purchasing in corporate social responsibility: a structural equation analysis. Journal of business Logistics 25 (1), 145-186.

Central Manchester University Hospitals NHS Foundation Trust, 2016. Procurement Transformation Plan (PTP).

Correia, F., Howard, M., Hawkins, B., Pye, A., Lamming, R., 2013. Low carbon procurement: An emerging agenda. Journal of Purchasing and Supply Management 19 (1), 58-64.

Cox, A., Chicksand, D., Ireland, P., 2005. Sub-optimality in NHS sourcing in the UK: Demandside constraints on supply-side improvement. Public Administration 83 (2), 367-392.

Cresswell, K. M., Sheikh, A., 2015. Health information technology in hospitals: current issues and future trends. Future Hospital Journal 2 (1), 50-56.

Customer Board Members, 2012. NHS Supply Chain Customer Board Procurement Metrics.

Davison, B., Sebastian, R. J., 2011. A detailed analysis of the relationship between contract administration problems and contract types. Journal of Public Procurement 11 (1), 108.

Department of Health, 2016. NHS Procurement \& Commercial Standards Towards Excellence. Version 3.

Elkington, J., 2002. Cannibals with Forks: The Triple Bottom Line of 21st Century Business reprint, Capstone.

Emmett, S., Crocker, B., 2008. Excellence in Procurement: How to optimise costs and add value. Cambridge academic.

Erridge, A., Hennigan, S., 2012. Sustainable procurement in health and social care in Northern Ireland. Public Money \& Management 32 (5), 363-370.

European Commision, 2003. Commission Recommendation of 6 May 2003 concerning the definition of micro, small and medium-sized enterprises. 
Feeley, T. H., O’Mally, A. K., 2015. Getting by with a little help from my friends. Organizations, Communication, and Health, 313-329.

Flynn, A., Davis, P., 2015. The policy-practice divide and sme-friendly public procurement. Environment and Planning C: Government and Policy, 0263774X15614667.

Grose, J., Bennallick, M., Nichols, A., Pahl, S., Richardson, J., 2012. Facilitating sustainable waste management behaviors within the health sector: A case study of the National Health Service (NHS) in southwest England, UK. Sustainability 4 (4), 630-642.

Grose, J., Richardson, J., 2013. Managing a sustainable, low carbon supply chain in the English National Health Service: The views of senior managers. Journal of health services research \& policy 18 (2), 83-89.

Harvie, J., Mikkelsen, L., Shak, L., 2009. A new health care prevention agenda: sustainable food procurement and agricultural policy. Journal of hunger \& environmental nutrition 4 (34), 409-429.

Hayes, G., 2010. The NHS information technology (IT) and social care review 2009: a synopsis. Journal of Innovation in Health Informatics 18 (2), 81-88.

Hinrichs, S., Jahagirdar, D., Miani, C., Guerin, B., Nolte, E., 2014. Experience of procurement and supply chain management in the health sector in selected high-income countries. NIHR Journals Library: December 2014.

Hong, P., Kwon, H.-B., 2012. Emerging issues of procurement management: a review and prospect. International Journal of Procurement Management 5 (4), 452-469.

Hywel Dda University Health Board, 2016. NHS Wales Shared Services Partnership Performance report January 2016 - March 2016.

Kerley, R., Wynn, D., 1991. Competitive tenderingthe transition to contracting in Scottish local authorities. Local Government Studies 17 (5), 33-51. 
Lindgreen, A., Swaen, V., Maon, F., Walker, H., Brammer, S., 2009. Sustainable procurement in the United Kingdom public sector. Supply Chain Management: An International Journal $14(2), 128-137$.

Loader, K., 2011. Are public sector procurement models and practices hindering small and medium suppliers? Public Money \& Management 31 (4), 287-294.

McCue, C. P., Pitzer, J. T., 2005. Fundamentals of leadership and management in public procurement. NIGP.

Moffett, S., Walker, T., 2015. Knowledge Management in the Public Sector: UK Case Study Perspectives. Springer International Publishing, pp. 67-104.

Munoz, S.-A., 2009. Social enterprise and public sector voices on procurement. Social Enterprise Journal 5 (1), 69-82.

NHS Supply Chain, 2013. Meeting the procurement challenge, briefing paper, issue 0012013.

NWSSP, 2015. Procurement Services Sustainable Procurement Policy, NHS Wales.

Oruezabala, G., Rico, J.-C., 2012. The impact of sustainable public procurement on supplier management the case of French public hospitals. Industrial Marketing Management 41 (4), $573-580$.

Parabl, 2016. Parabl talking therapies partnership, http://www.parabl.org.uk/english/.

Powys Teaching Health Board, 2016. NHS Wales Shared Partnership Performance report April 2016 - June 2016.

Preuss, L., 2009. Addressing sustainable development through public procurement: the case of local government. Supply Chain Management: An International Journal 14 (3), 213-223.

Public Policy Institute for Wales, 2016. Efficiency and the NHS Wales Funding Gap.

Reijonen, H., Tammi, T., Saastamoinen, J., 2014. SMEs and public sector procurement: Does entrepreneurial orientation make a difference? International Small Business Journal, 1-19. 
Salleh, N. A. M., Rohde, F., Green, P., 2006. The effect of enacted capabilities on adoption of a government electronic procurement system by Malaysian SMEs. Electronic Markets 16 (4), $292-311$.

Sarkis, J., Zhu, Q., Lai, K.-h., 2011. An organizational theoretic review of green supply chain management literature. International Journal of Production Economics 130 (1), 1-15.

Shaw, J., 2011. Business population estimates for the UK and regions. Economic and Labour Market Review 5 (4), 47-67.

Srivastava, S. K., 2007. Green supply-chain management: a state-of-the-art literature review. International journal of management reviews 9 (1), 53-80.

Thai, K. V., 2008. International handbook of public procurement. CRC Press.

Thomson, J., Jackson, T., 2007. Sustainable procurement in practice: lessons from local government. Journal of Environmental Planning and Management 50 (3), 421-444.

Tudor, T., Baddley, J., Mayhew-Manchòn, L., 2015. Examining the uptake of low-carbon approaches within the healthcare sector: case studies from the National Health Service in England. International Journal of Healthcare 1 (1), p61.

Tudor, T. L., Marsh, C., Butler, S., Van Horn, J., Jenkin, L., 2008. Realising resource efficiency in the management of healthcare waste from the Cornwall National Health Service (NHS) in the UK. Waste Management 28 (7), 1209-1218.

Van Raaij, E. M., Brandon-Jones, A., Reunis, M., Laming, R., 2007. The impact of eprocurement quality factors on user acceptance of e-procurement systems. In: Proceedings of the 16th IPSERA Conference, Bath, UK.

Walker, H., 2015. New development: Public procurement research at IPSERA-aligning research and practice, and future trends. Public Money \& Management 35 (2), 141-144.

Walker, H., Brammer, S., 2012. The relationship between sustainable procurement and eprocurement in the public sector. International Journal of Production Economics 140 (1), 256-268. 
Walker, H., Di Sisto, L., McBain, D., 2008. Drivers and barriers to environmental supply chain management practices: Lessons from the public and private sectors. Journal of purchasing and supply management 14 (1), 69-85.

Walker, H., Preuss, L., 2008. Fostering sustainability through sourcing from small businesses: public sector perspectives. Journal of Cleaner Production 16 (15), 1600-1609. 